Universidade Tecnológica Federal do Paraná - UTFPR

Campus Ponta Grossa - Paraná - Brasil

ISSN: 1981-3686/ v. 08, n. 01: p. 1227-1236, 2014

D.O.I.: $10.3895 / \mathrm{S} 1981-36862014000100008$
Revista Brasileira de Tecnologia

Agroindustrial

\title{
PRODUÇÃO EM MATRIZ SÓLIDA E CARACTERIZAÇÃO PARCIAL DAS PROTEASES DE COGUMELO COMESTÍVEL DA FLORESTA AMAZÔNICA
}

\section{PRODUCTION IN SOLID MATRIX AND PROTEASES PARTIAL CHARACTERIZATION OF EDIBLE MUSHROOM FROM AMAZON RAIN FOREST}

\author{
Tamiris Rio Branco da Fonseca ${ }^{1}$; Jéssica Ferreira Barroncas ${ }^{2}$; Maria Francisca Simas Teixeira ${ }^{3}$ \\ ${ }^{1}$ Universidade Federal do Amazonas - UFAM - Manaus - Brasil- tamirisrbfo @ hotmail.com; \\ jessicabarroncas@gmail.com; mteixeira@ufam.edu.br
}

\begin{abstract}
Resumo
Enzimas proteolíticas constituem um dos mais importantes grupos catalisadores, tem ampla utilização comercial e industrial. Entre essas, as proteases de origem fúngica apresentam vantagens como alta diversidade, fácil produção em larga escala e recuperação. O objetivo deste estudo foi avaliar a produção e caracterizar parcialmente proteases do extrato bruto de Pleurotus ostreatoroseus cultivado em substratos agroindustriais. A cultura matriz foi preparada em ágar batata dextrose acrescida de extrato de levedura 0,5\% (p/v). A produção das enzimas proteolíticas foi realizada por fermentação semi-sólida utilizando substratos agroindustriais. A fermentação foi conduzida durante 15 dias sob duas condições de cultivo (presença e ausência de luz). Para determinação da atividade e caracterização parcial das proteases, o extrato bruto foi filtrado sucessivamente em tecido de algodão e membrana polietersulfônica de 0,22 $\mu \mathrm{m}$. Os resultados demonstraram que os resíduos foram fontes para a produção de proteases com $\mathrm{pH}$ variando de levemente ácido a alcalino e temperatura ótima a $25^{\circ} \mathrm{C}$ e $40^{\circ} \mathrm{C}$.
\end{abstract}

Palavras-chave: Pleurotus ostreatoroseus; fermentação em estado sólido; enzimas.

\section{Introdução}

No mercado mundial de enzimas as proteases predominam na indústria de detergentes, farmacêutica, cerveja, couro, alimentos, como coagulante na fabricação de queijo e para recuperação da prata usada no filme de raios-X (GENÇKAL, 2004; CUI et al., 2007; SABOTIC et al., 2007; DABOOR et al., 2010). Proteases também participam da síntese e degradação de proteínas, da conidiogênese e descarga conidial, germinação, modificação enzimática, nutrição e regulação da expressão gênica (CUI et al., 2007; NAKAMURA et al., 2011; ZHENG et al., 2011).

As enzimas proteolíticas têm origem de diversas fontes vegetal, animal e microorganismos procariontes e eucariontes, entre estes, os fungos são produtores eficientes, predominando espécies de Aspergillus e Penicillium (SANDHYA et al., 2005). Entre os fungos, os cogumelos estão se tornando uma fonte atraente de compostos bioativos, além de usado tipicamente como alimento. Nos últimos anos, diversos cogumelos comestíveis são também citados como fontes de enzimas, incluindo proteases fibrinolíticas, a exemplo de P. eryngii (CHA et al., 2010), 
Flammulina velutipes, $P$. ostreatus, Grifola frondosa, Tricholoma saponaceum, Armillaria mellea e Cordyceps militaris estão relatadas nas citações de Park et al. (2007) e Nakamura et al. (2011). Outras proteases já foram detectadas nos extratos oriundos do cultivo de P. ostreatus (SHIN e CHOI, 1998; PALMIEIRI et al., 2001; SHABA e BABA, 2012), P. citrinopileatus (CUI et al., 2007) e P. sajor-caju (RAVIKUMAR et al., 2012;).

Já que cogumelos crescem na natureza sob condições de estado sólido, esse hábito se tornou vantajoso para utilização no desenvolvimento de bioprocessos utilizando resíduos agrícolas como substrato (REDDY et al., 2003). Esta tecnologia denominada de fermentação semi-sólida (FSS) continua sendo um processo para produção de proteases extracelulares por ser apropriada para o crescimento de fungos que exigem umidade baixa para crescimento quando comparados às bactérias. A FSS oferece, economicamente, certas vantagens, produtividade volumétrica superior, uso de equipamentos simples e de substratos de baixo custo, assim como, gasto de energia reduzido comparado a fermentação submersa (PANDEY, 2003; PINTO et al., 2005; SANTOS et al., 2006; RAVIKUMAR et al., 2012) .

O objetivo deste trabalho foi investigar a produção de proteases extracelulares por Pleurotus ostreatoroseus cultivado em resíduos agroindustriais na presença e ausência de luz para caracterização parcial dessas enzimas no extrato bruto.

\section{Material e Métodos}

\section{Cultivo e Manutenção de Pleurotus ostreatoreoseus}

O cogumelo avaliado neste estudo foi $P$. ostreatoroseus cedido pela Coleção de Cultura DPUA da Universidade Federal do Amazonas. As culturas estoque foram mantidas por 8 dias, a $25^{\circ} \mathrm{C}$ em ágar batata dextrose com extrato de levedura 0,5\% [p/v (BDA+YE)], em placas de Petri. Para manutenção de cultura viável, a cada 30 dias foram preparados novos subcultivos.

\section{Inóculo}

Do subcultivo de $P$. ostreatoroseus foram retirados discos miceliais medindo $8 \mathrm{~mm}$ de diâmetro e transferidos para BDA+YE, em placa de Petri. As culturas foram incubadas a $25{ }^{\circ} \mathrm{C}$ por 8 dias, na ausência de luz para serem utilizadas como inóculo na fermentação semi-sólida (KIRSCH et al., 2011).

\section{Preparo do Substrato, Inoculação e Condições de Fermentação Semi-Sólida}

Os substratos agroindustriais foram adquiridos na cidade de Manaus, Amazonas com exceção do farelo de arroz que foi obtido na cidade de Boa Vista, Roraima. Para fermentação semisólida, no laboratório, a casca de cupuaçu (Theobroma grandiflorum Willd Ex-Spreng Schum), a 
casca e coroa de abacaxi (Ananas comosus (L.) Merril) e a semente de açaí (Euterpe oleracea Mart.) foram fragmentadas e tratadas com solução desinfetante para hortifrutícolas, conforme as recomendações do fabricante. A casca de cupuaçu foi suplementada com farelo de arroz e a serragem e semente de açaí, ambas suplementadas com casca e coroa de abacaxi (Tabela 1). A umidade foi ajustada para $60 \%$ e o $\mathrm{pH} 6,5$.

\begin{tabular}{llc} 
Tabela 1. Substratos agroindustriais e porcentagens utilizadas na fermentação semi- \\
sólida para crescimento e produção de proteases por P. ostreatoroseus. \\
\hline Substratos & \multicolumn{3}{c}{ Concentração } \\
\cline { 2 - 3 } Agroindustriais & Serragem & \multicolumn{2}{c}{$20 \%$} \\
\hline SER + CsAb & Serragem & Casca de abacaxi \\
$\mathrm{SER}+\mathrm{CrAb}$ & Semente de açaí & Coroa de abacaxi \\
$\mathrm{Sac}+\mathrm{CsAb}$ & Semente de açaí & Casca de abacaxi \\
$\mathrm{Sac}+\mathrm{CrAb}$ & Casca de cupuaçu & Coroa de abacaxi \\
$\mathrm{CC}+\mathrm{FA}$ & Farelo de arroz \\
\hline
\end{tabular}

Na parte inferior de cada tubo de ensaio, medindo $200 \mathrm{~mm}$ x $25 \mathrm{~mm}$ foi colocado algodão umedecido com água destilada, em seguida os resíduos foram colocados nos tubos até preencher 15 cm de altura (PALHETA et al, 2011). Todos os tubos foram tamponados com algodão, identificados e esterilizados a $121{ }^{\circ} \mathrm{C}$ por 45 minutos. Após resfriamento, o inóculo (três discos miceliais de $8 \mathrm{~mm}$ de diâmetro) foi semeado na superfície dos substratos esterilizados. A fermentação semi-sólida foi conduzida a $25{ }^{\circ} \mathrm{C}$, em ambiente com umidade a $60 \%$, na presença ou ausência de luz durante 15 dias. Todos os experimentos foram realizados em triplicata.

\section{Extração das Enzimas}

As proteases foram extraídas em água destilada esterilizada na proporção 2:20 g (resíduo miceliado/mL de água destilada) em frascos de Erlenmeyer de $125 \mathrm{~mL}$. Os frascos foram mantidos a $30{ }^{\circ} \mathrm{C}, 180 \mathrm{rpm}$. Após 30 minutos os extratos brutos foram recuperados por filtração em tecido de

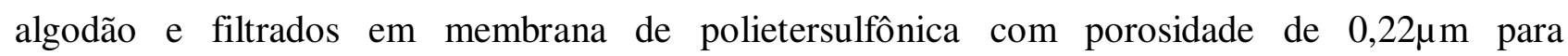
determinação da atividade das proteases (CHUTMANOP et al., 2008).

\section{Determinação da atividade de proteases}

A atividade proteolítica foi determinada em $0,15 \mathrm{~mL}$ do extrato bruto adicionado a $0,25 \mathrm{~mL}$ de azocaseína $1 \%(\mathrm{p} / \mathrm{v})$, em tampão Tris- $\mathrm{HCl}$ 0,1 M, pH 7,2. As amostras e os brancos foram preparados em triplicada e incubados a $25^{\circ} \mathrm{C}$ por 1 hora em câmara escura. A reação foi interrompida com 1,2 mL de TCA [ácido tricloroacético $10 \%(\mathrm{p} / \mathrm{v})$ ] seguido de centrifugação por 10 minutos a $4{ }^{\circ} \mathrm{C}$. Do sobrenadante foi retirado $0,8 \mathrm{~mL}$ e acrescentado a $1,4 \mathrm{~mL} \mathrm{NaOH} 1 \mathrm{M}$. Uma unidade de atividade proteolítica foi definida como a quantidade de enzima capaz de produzir um aumento na absorbância a 440 nm de 0,1 em 1 hora (MOREIRA et al., 2001; KIRSCH et al., 2012). 
Determinação do efeito da temperatura e do $\mathrm{pH}$ na atividade das proteases

$\mathrm{O}$ efeito do $\mathrm{pH}$ foi determinado na faixa de 5,0 a 10,0 em tampão citrato, fosfato e carbonato-bicarbonato a $0,1 \mathrm{M}$. O efeito da temperatura na atividade proteolítica foi avaliado na faixa de $25{ }^{\circ} \mathrm{C}$ a $60{ }^{\circ} \mathrm{C}$. A atividade das proteases foi determinada conforme citado no item 2.5.

\section{Análise estatística}

Os resultados foram submetidos à análise estatística descritiva (média e desvio padrão), análise de variância (ANOVA) e a comparação das médias foram realizadas pelo teste de Tukey $(\mathrm{p} \leq 0,05 \%)$ utilizando o software Minitab 16.

\section{Resultados e Discussão}

A Figura 1 mostra a produção de proteases por $P$. ostreatoroseus em casca de cupuaçu, semente de açaí, serragem, casca e coroa de abacaxi e farelo de arroz, substratos agroindustriais utilizados na fermentação semi-sólida. As enzimas foram produzidas em todos os substratos, cujas médias de atividade proteolítica $(7,89 \mathrm{U} / \mathrm{mL})$ de valores significativos foram determinadas no cultivo onde o substrato foi casca de cupuaçu suplementado com farelo de arroz (CC+FA), na presença de luz. No mesmo substrato, na ausência de luz foi determinado o segundo maior valor de atividade proteolítica $(4,50 \mathrm{U} / \mathrm{mL})$.

Do total de substratos utilizados na fermentação semi-sólida, CC+FA e SER+CsAb foram os melhores substratos para produção das proteases. Os resultados indicaram ainda que o valor da atividade proteolítica variou de acordo com o tipo de substrato agroindustrial, predominando nos cultivos mantidos na presença de luz e no substrato contendo farelo de arroz (Figura 1). Além disso, na ausência de luz, a redução da atividade proteolítica em todos os substratos foi aproximadamente de $43 \%$ quando comparado aos valores da atividade na presença de luz.

Proteases são produzidas por diferentes fungos filamentosos, leveduras e bactérias em cultivo submerso ou em matriz sólida (RAO et al., 1998; OLIVEIRA et al., 2006). Porém, para o desenvolvimento de modelos apropriados o alvo está no estabelecimento das relações entre a fisiologia dos fungos e os fatores físico-químicos, considerando que as diversas espécies exigem para crescimento umidade em torno de 40-60\%. Além disso, a seleção do substrato para uso na fermentação semi-sólida depende de vários fatores, compreendendo principalmente a natureza, o custo e a disponibilidade do substrato (SINGHANIA et al., 2009).

Entre os fungos filamentosos são inúmeros os trabalhos que citam diversas espécies anamórficas como produtoras de proteases, com predominância Aspergillus e Penicillium. Em contrapartida os estudos que referem cogumelos como fontes dessas enzimas são raros, uma vez 
que, as propriedades que sempre despertaram o interesse por esses fungos são o valor nutricional e o medicinal (WANI et al., 2010).

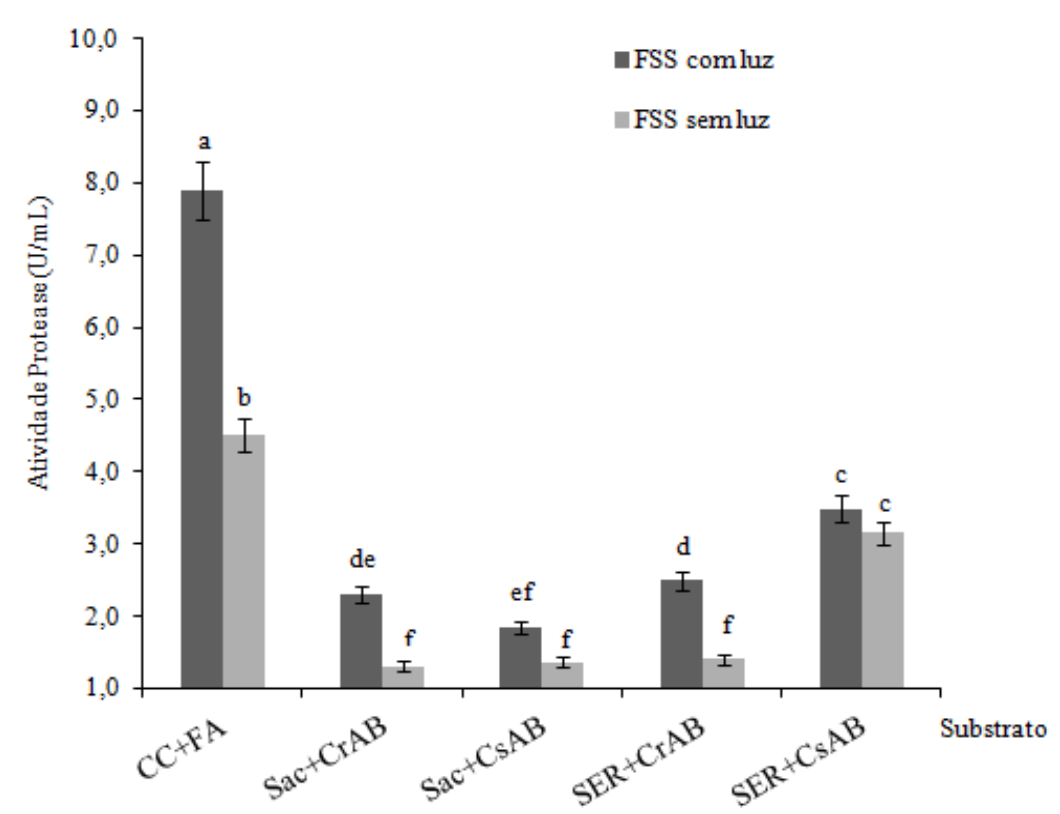

Figura 1 - Média da atividade de proteases produzida por P. ostreatoroseus em substratos agroindustriais durante 15 dias por fermentação semi-sólida, em duas condições de cultivo, presença e ausência de luz. CC+FA (casca de cupuaçu+farelo de arroz); Sac+CsAb (semente de açaítcasca de abacaxi); $\mathrm{Sac}+\mathrm{CrAb}$ (semente de açaítcoroa de abacaxi); SER+CsAb (Serragem+casca de abacaxi); SER+CrAb (Serragem+ coroa de abacaxi).

Em se tratando dos cogumelos, a atividade de proteases está demonstrada em Agaricus bisporus, Pleurotus citrinopileatus, Grifola frondosa, Pleurotus ostreatus, Termitomyces albuminosus, Pleurotus sajor-caju e por Sabotic et al. (2007) para 43 basidiomicetos (BURTON et al., 1997; Cui et al., 2007; NISHIWAKI et al., 2009; CAMPOS et al., 2010; ZHENG et al., 2011; RAVIKUMAR et al., 2012). Os resultados desta investigação revelaram a produção de proteases por P. ostreatoroseus e o potencial da casca do fruto do cupuaçuzeiro ( $T$. grandiflorum) adicionado de farelo de arroz como substratos para produção máxima das enzimas. O uso de resíduos da fruticultura amazônica na tecnologia da fermentação, entre outros benefícios, pode reduzir a contaminação ambiental e o custo de produção de compostos bioativos. No setor comercial as proteases têm importantes aplicações na indústria de detergente, alimentos, couro, produtos farmacêuticos e diagnósticos, gestão de resíduos e recuperação de prata dos filmes de raios-X (TREMACOLDI e CARMONA, 2005; NAKAMURA et al., 2011).

Quanto ao efeito da temperatura na atividade das proteases de P. ostreatoroseus (Figura 2), os dados mostram que entre $25^{\circ} \mathrm{C}$ e $60{ }^{\circ} \mathrm{C}$ as enzimas permaneceram ativas por 60 minutos. Em média, a temperatura ótima para a atividade proteolítica foi determinada a $40{ }^{\circ} \mathrm{C}$, em todos os extratos dos cultivos mantidos na presença de luz (Figura 2A). Nos cultivos na ausência de luz, o perfil da atividade foi semelhante aos incubados na presença de luz, com exceção do extrato bruto 
obtido da fermentação em serragem e coroa de abacaxi (SER+CrAb), cuja atividade ótima foi determinada a $25{ }^{\circ} \mathrm{C}$ (Figura $2 \mathrm{~B}$ ). Ainda na figura $2 \mathrm{~A}$ e $2 \mathrm{~B}$ pode ser observado que a atividade enzimática na faixa de $50{ }^{\circ} \mathrm{C}$ a $60{ }^{\circ} \mathrm{C}$ foi reduzida de forma gradual sem causar a inativação das enzimas proteolíticas.

Com base nos resultados apresentados ficou evidente que nos extratos recuperados dos cultivos $\mathrm{CC}+\mathrm{FA}$ e SER+CsAb, em todas as temperaturas, a atividade das proteases foi superior quando comparado aos demais substratos (Figura 2A e 2B). Dados semelhantes foram demonstrados para subtilisina, protease produzida por G. frondosa (NISHIWAKI et al., 2009).
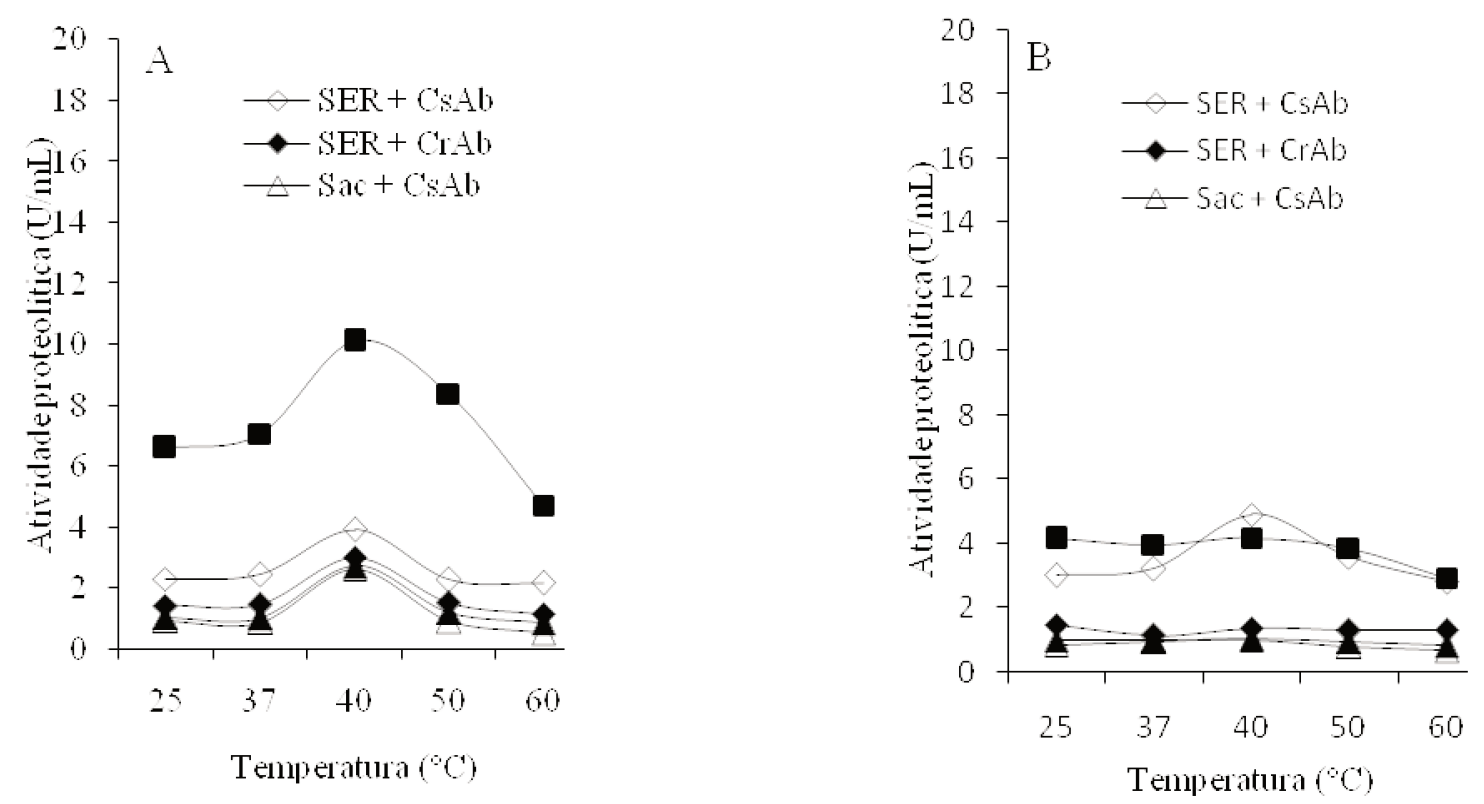

Figura 2. Efeito da temperatura na atividade das proteases de $P$. ostreatoroseus produzidas por fermentação semi-sólida em substratos agroindustriais durante 15 dias na presença (A) e ausência de luz (B). CC+FA (casca de cupuaçu+farelo de arroz); Sac+CsAb (semente de açaí+casca de abacaxi); Sac+CrAb (semente de açaí+coroa de abacaxi); SER+CsAb (Serragem+casca de abacaxi); SER+CrAb (Serragem+ coroa de abacaxi).

O efeito do $\mathrm{pH}$ na atividade das proteases foi determinado na faixa de 5,0 a 10,0. Os dados mostrados na figura 3 evidenciaram o perfil dessas enzimas de P. ostreatoroseus que na totalidade foram ativas nas condições experimentais. Contudo nos extratos provenientes dos cultivos realizados na presença de luz a atividade máxima foi determinada em pH 6,0 quando na fermentação foi utilizado $\mathrm{CC}+\mathrm{FA}$, Sac+CrAb e $\mathrm{Sac}+\mathrm{Cs} A b$. Nos demais substratos, SER+CsAb e $\mathrm{SER}+\mathrm{CrAb}$, o maior valor de atividade proteolítica foi determinada em $\mathrm{pH}$ 7,0 (Figura 3A), resultado semelhante foi obtido para protease do basidiomas de Cordyceps militaris (CHOI et al., 2011).

Na ausência de luz, a atividade ótima foi predominante em pH 6,0 nos extratos procedentes da fermentação em CC+FA, SER+CsAb, Sac+CsAb e Sac+CrAb, em ordem decrescente ao valor da atividade proteolítica. Nessa mesma condição, a atividade ótima das proteases excretadas em 
SER+CrAb foi determinada $\mathrm{em} \mathrm{pH} \mathrm{8,0,} \mathrm{assim} \mathrm{como} \mathrm{o} \mathrm{obtido} \mathrm{para} \mathrm{a} \mathrm{protease} \mathrm{purificada} \mathrm{de} P$. sajorcaju cultivado em farinha de milho adicionado de farelo de trigo (RAVIKUMAR et al., 2012).
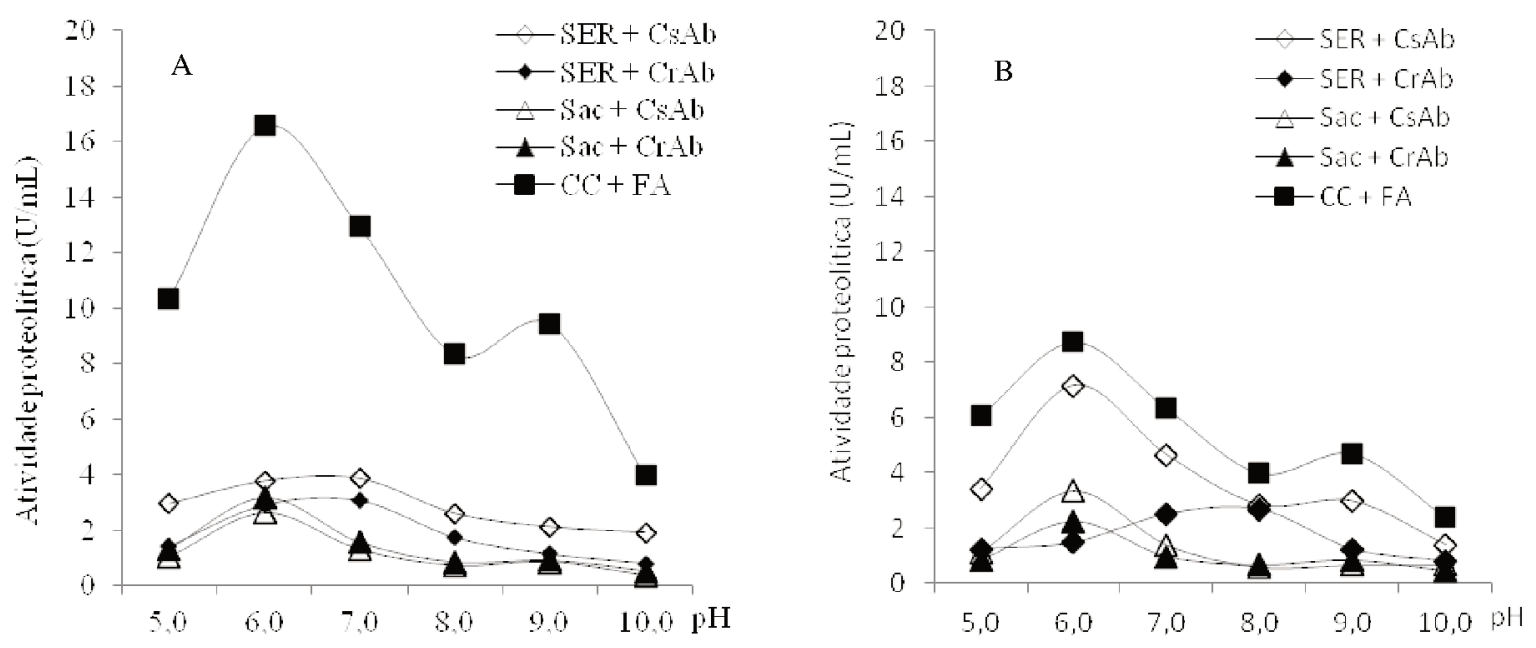

Figura 3. Efeito do $\mathrm{pH}$ na atividade das proteases de $P$. ostreatoroseus produzidas por fermentação semi-sólida em substratos agroindustriais durante 15 dias na presença (A) e ausência de luz (B). CC+FA (casca de cupuaçu+farelo de arroz); Sac+CsAb (semente de açaítcasca de abacaxi); Sac+CrAb (semente de açaí+coroa de abacaxi); SER+CsAb (Serragem+casca de abacaxi); SER+CrAb (Serragem+ coroa de abacaxi).

A produção de proteases extracelulares com atividade ótima em $\mathrm{pH} 6,0,7,0$ e 8,0 por $P$. ostreatoroseus provavelmente esteja associada a necessidade do cogumelo em hidrolisar os diferentes substratos disponíveis como fonte de nutrientes protéicos. As proteases do basidioma de P. ostreatus e P. citrinopileatus apresentaram pH ótimo levemente ácido a alcalino (SHIN E CHOI, 1998; CUI et al., 2007). Cha et al. (2010) para P. eryngii, nos extratos dos cultivos em sabugo de milho adicionado de farelo de arroz obtiveram máxima atividade enzimática em pH 5,0. Nirmal et al. (2011), citam que os fungos produzem proteases ácidas, neutras e alcalinas, inclusive uma espécie pode produzir mais de um tipo dessas enzimas que podem ser ativas a uma ampla faixa de $\mathrm{pH}(4,0$ a 11,0$)$.

Palmieri et al. (2001) reportaram o pH alcalino para atividade ótima de subtilisina, uma serino protease produzida por P. ostreatus. Em outro relato feito por Cui et al (2007), para uma serino protease extraída dos basidiomas in natura de $P$. citrinopileatus a máxima atividade proteolítica foi determinada no pH 10,0. Nos resultados apresentados por Nishiwaki et al. (2009), proteases de Grifola frondosa na avaliação da especificidade de substrato expressou pH ótimo 3,0 e 7,0 para hemoglobina e caseína, respectivamente. 


\title{
4 Conclusões
}

Os substratos agroindustriais (casca de cupuaçu, semente de açaí e serragem) e os respectivos suplementos (farelo de arroz, coroa e casca de abacaxi) se mostraram como potenciais substratos em fermentação semi-sólida para produção de enzimas proteolíticas por $P$. ostreatoroseus. No entanto, nos cultivos mantidos sob luz, casca de cupuaçu e farelo de arroz foi a mistura de substrato mais eficiente para produção das proteases, com atividade ótima em pH 6,0 e a $40{ }^{\circ} \mathrm{C}$, características permitem a aplicação na indústria farmacêutica, têxtil, alimentícia e química.

\section{Agradecimentos}

Ao Conselho Nacional de Desenvolvimento Científico e Tecnológico (CNPq), a Coordenação de Aperfeiçoamento de Pessoal de Nível Superior-CAPES, a Universidade Federal do Amazonas-UFAM pelo apoio financeiro e a todas as pessoas que colaboraram para a realização deste artigo.

\begin{abstract}
Proteolytic enzymes are one of the most important enzyme group that have extensive commercial and industrial use. The fungal proteases have advantages because of their high diversity, easier large scale production and recovery. This study was conducted to evaluate and partially characterize the proteases of the crude extract of Pleurotus ostreatoroseus cultivated on agroindustrial substrate. The mushroom culture was prepared in potato dextrose agar with yeast extract $0.5 \%(w / v)$. The production of proteolytic enzymes was performed by solid state fermentation in agroindustrial substrate for 15 days under two growth conditions (in the presence and absence of light). The crude extract was successively filtrated in cotton fabric and in a membrane pore of $0.22 \mu m$.Then it was used to determinate the protease activity and the parcial characterization of the enzymes. The results demonstrated that the residues were good sources to produce proteases with $\mathrm{pH}$ ranging from slightly acidic to alkaline and with optimum temperature at $25^{\circ} \mathrm{C}$ and $40^{\circ} \mathrm{C}$.
\end{abstract}

Key-words: Pleurotus ostreatoroseus; solid-state fermentation; enzymes.

\section{Referências}

BURTON, K. S.; PARTIS, M. D.; WOOD, D. A.; THURSTON, C. F. Accumulation of serine proteinase in senescent sporophores of the cultivated mushroom, Agaricus bisporus. Mycology Research, v. 101, n. 2, p. 146-152, 1997. http://dx.doi.org/10.1017/S0953756296002316

CAMPOS, C.; DIAS, D. C.; VALlE, J. S.; COLAUTO, N. B.; LINDE, G. A. Produção de biomassa, proteases e exopolissacarídeos por Pleurotus ostreatus em cultivo líquido. Arquivo de Ciências Veterinárias e Zoologia, v. 13, n. 1, p. 19-24, 2010.

CHA, W.-S.; PARK, S.-S.; KIM, S.-J.; CHOI, D. Biochemical and enzymatic properties of a fibrinolytic enzyme from Pleurotus eryngii cultivated under solid-state conditions using corn cob. Bioresource Technology, v. 101, p. 64756481, 2010. http://dx.doi.org/10.1016/j.biortech.2010.02.048

CHOI, D.; CHA, W.-S.; PARK, N.; KIM, H.-W.; LEE, J.-H., PARK, J. S.; PARK, S.-S. Purification and characterization of a novel fibrinolytic enzyme from fruiting bodies of Korean Cordyceps militaris. Bioresource Technology, v. 102, p. 3279-3285, 2011. http://dx.doi.org/10.1016/j.biortech.2010.10.002

CHUTMANOP, J.; CHUICHULCHERM, S.; CHISTI, Y.; SRINOPHAKUN, P. Protease production by Aspergillus oryzae in solid-state fermentation using agroindustrial substrates. Journal of Chemical Technology and Biotechnology, v. 83, p. 1012-1018, 2008. http://dx.doi.org/10.1002/jctb.1907 
CUI, L.; LIU, Q. H.; WANG, H. X.; NG, T. B. An alkaline protease from fresh fruiting bodies of the edible mushroom Pleurotus citrinopileatus. Applied Microbiology and Biotechnology, v. $75, \quad$ p. $\quad 81-85, \quad 2007$. http://dx.doi.org/10.1007/s00253-006-0801-z

DABOOR, S. M.; BUDGE, S. M.; GHALY, A. E.; BROOKS, S.-L.; DAVE, D. Extraction and purification of collagenase enzymes: A critical review. American Journal of Biochemistry and Biotechnology, v. 6, n. 4, p. 239263, 2010. http://dx.doi.org/10.3844/ajbbsp.2010.239.263

GENÇKAL, H. Studies on alkaline protease production from Bacillus sp. İzmir, 2004, 98 f.. Dissertação (Mestrado em Biotecnologia) - Department of Biotechnology and Bioengineering - İzmir Institute of Technology.

KIRSCH, L. S.; PINTO, A. C. S.; PORTO, T. S.; PORTO, A. L. F.; TEIXEIRA, M. F. S. The influence of different submerged cultivation conditions on mycelial biomass and protease production by Lentinus citrinus Walleyn et Rammeloo DPUA 1535 (Agaricomycetideae). International Journal of Medical Mushrooms, v. 13, n. 2, p. 185-192, 2011. http://dx.doi.org/10.1615/IntJMedMushr.v13.i2.110

KIRSCH, L. S.; PINTO, A. C. S.; TEIXEIRA, M. F. S.; PORTO, T. S.; PORTO, A. L. F. Partition of proteases from Lentinus citrinus DPUA 1535 by the Peg/Phosphate Aqueous Two-Phase System. Química Nova, v. 35, n. 10, p. 1912915, 2012. http://dx.doi.org/10.1590/S0100-40422012001000004

MOREIRA, K. A; CAVAlCANTI, M. T. H; DUARTE, H. S; TAMBOURGI, E. B; MELO, E. H. M; SILVA, V. L.; PORTO, A. L.; LIMA, J. S. F. Partial characterization of proteases from Streptomyces clavuligerus using a inexpensive medium. Brazilian Journal of Microbiology, v. 32, p. 215-220, 2001. http://dx.doi.org/10.1590/S151783822001000300010

| NAKAMURA, M.; IKETANI, A.; SHIOI, Y. -A survey of proteases in edible mushrooms with synthetic peptides as substrates. Mycoscience, v. 52, p. 234-241, 2011. http://dx.doi.org/10.1007/S10267-010-0089-9

NIRMAL, N. P.; SHANKAR, S.; LAXMAN, R. S. Fungal proteases: An overview. Internacional Journal of Biotechnology and Biosciences, v. 1, n. 1, p. 1-40, 2011.

NISHIWAKI, T.; ASANO, S.; OHYAMA, T. Properties and substrate specificities of proteolytic enzymes from the edible basidiomycete Grifola frondosa. Journal of Bioscience and Bioengineering, v. 107, n. 6, p. 605-609, 2009. http://dx.doi.org/10.1016/j.jbiosc.2009.01.008

OLIVEIRA, A. N.; OLIVEIRA, L. A.; ANDRADE, J. S.; CHAGAS JÚNIOR, A. F. Atividade enzimática de isolados de rizóbia nativos da Amazônia central crescendo em diferentes níveis de acidez. Ciência e Tecnologia de Alimentos, v.26, n.1, p.204-210, 2006. http://dx.doi.org/10.1590/S0101-20612006000100032

PALHETA, R. A.; VIEIRA, J. N.; NEVES, K. C. S.; TEIXEIRA, M. F. S. Crescimento micelial vertical de duas espécies de Pleurotus em resíduo agroindustrial da Amazônia utilizando planejamento fatorial. Caderno de Pesquisa série Biologia, v. 23, n. 3, p. 52-60, 2011.

PALMIERI, G.; BIANCO, C.; CENNAMO, G.; GIARDINA, P.; MARINO, G.; MONTI, M.; SANNIA, G. Purification, characterization, and functional role of a novel extracellular protease from Pleurotus ostreatus. Applied and Environmental Microbiology, v. 67, n. 6, p. 2754-2759, 2001. http://dx.doi.org/10.1128/AEM.67.6.27542759.2001

PANDEY, A. Solid-state fermentation. Biochemical Engineering Journal, v. 13, p. 81-84, 2003. http://dx.doi.org/10.1016/S1369-703X(02)00121-3

PARK, S.-E.; LI, M.-H.; KIM, J.-S.; SAPKOTA, K.; KIM, J.-E.; CHOI, B.-S.; YOON, Y.-H.; LEE, J.-C.; LEE, H.-H.; KIM, C.-S.; KIM, S.-J. Purification and characterization of a fibrinolytic protease from a culture supernatant of Flammulina velutipes mycelia. Bioscience, Biotechnology and Biochemistry, v. 71, n. 9, p. 2214-2222, 2007. http://dx.doi.org/10.1271/bbb.70193

PINTO, G. A. S.; BRITO, E. S.; ANDRADE, A. M. R.; FRAGA, S. L. P.; TEIXEIRA, R. B. Fermentação em estado sólido: uma alternativa para o aproveitamento e valorização de resíduos agroindustriais tropicais. Fortaleza, CE: Embrapa Agroindústra Tropical (Comunicado técnico, 102), 5 p., 2005.

RAO, M. B.; TANKSALE, A. M.; GHATGE, M. S.; DESH-PANDE, V. V. Molecular and biotechnological aspects of microbial proteases. Microbiology and Molecular Biology Reviews, v. 62, n. 3, p. 597-635, 1998. 
RAVIKUMAR, G.; GOMATHI, D.; KALAISELVI, M.; UMA, C. A protease from the medicinal mushroom Pleurotus sajor-caju: production, purification and partial characterization. Asian Pacific Journal of Tropical Biomedicine, v. 2 , n. 1, p. 411-417, 2012. http://dx.doi.org/10.1016/S2221-1691(12)60198-1

REDDY, G. V.; RAVINDRA-BABUB, P.; KOMARAIAHC, P.; ROYA, K. R. R. M.; KOTHARI, I. L. Utilization of banana waste for the production of lignolytic and cellulolytic enzymes by solid substrate fermentation using two Pleurotus species (P. ostreatus and P. sajor-caju). Process Biochemistry, v. 38, p.1457-1462, 2003. http://dx.doi.org/10.1016/S0032-9592(03)00025-6

SABOTIC, J.; TRCEK, T.; POPOVIC, T.; BRZIN, J. Basidiomycetes harbour a hidden treasure of proteolytic diversity. Journal of Biotechnology, v. 128, p. 297-307, 2007. http://dx.doi.org/10.1016/j.jbiotec.2006.10.006

SANDHYA, C.; SUMANTHA, A.; SZAKACS, G.; PANDEY, A. Comparative evaluation of neutral protease production by Aspergillus oryzae in submerged and solid-state fermentation. Process Biochemistry, v. 40, p. 26892694, 2005. http://dx.doi.org/10.1016/j.procbio.2004.12.001

SANTOS, D. T.; SARROUH, B. F.; SANTOS, J. C.; PÉREZ, V. H.; SILVA, S. S. Potencialidades e aplicações da fermentação semi-sólida em Biotecnologia. Janus: Revista de Pesquisa Científica, n. 4, 2006.

SHABA, A. M.; BABA, J. Screening of Pleurotus ostreatus and Gleophylum sepiarum strains for extracellular protease enzyme production. Bayero Journal of Pure and Applied Sciences, v. 5, n. 1, p. 187-190, 2012. http://dx.doi.org/10.4314/bajopas.v5i1.33

SHIN, H.-H.; CHOI, H.-S. Purification and characterization of cysteine protease from Pleurotus ostreatus. Bioscience, Biotechnology and Biochemistry, v.62, n.7, p.1416-1418, 1998. http://dx.doi.org/10.1271/bbb.62.1416

SINGHANIA, R. R.; PATEL, A. K.; SOCCOL, C. R.; PANDEY, A. Recent advances in solid-state fermentation. Biochemical Engineering Journal, v. 44, p. 13-18, 2009. http://dx.doi.org/10.1016/j.bej.2008.10.019

TREMACOLDI, C. R.; CARMONA, E. C. Production of extracellular alkaline proteases by Aspergillus clavatus. World Journal of Microbiology \& Biotechnology, v. 21, p. 169-172, 2005. http://dx.doi.org/10.1007/s11274-0042724-0

ZHENG, S.; WANG, H.; ZHANG, G. A novel alkaline protease from wild edible mushroom Termitomyces albuminosus. Acta Biochimica Polonica, v. 58, n. 2, p. 269-273, 2011.

WANI, B. A.; BODHA, R. H.; WANI, A. H. Nutritional and medicinal importance of mushrooms. Journal of Medicinal Plants Research, v. 4, n. 24, p. 2598-2604, 2010.

Submetido em 01 abr. 2013, Aceito para publicação em 20 dez. 2013. 